\title{
Aysheaia prolata from the Utah Wheeler Formation (Drumian, Cambrian) is a frontal appendage of the radiodontan Stanleycaris
}

\author{
Stephen Pates, Allison C. Daley, and Javier Ortega-Hernández \\ Acta Palaeontologica Polonica 62 (3), 2017: 619-625 doi:https://doi.org/10.4202/app.00361.2017
}

Aysheaia prolata, was described as the only lobopodian from the Drumian (Cambrian) Wheeler Formation in Utah, USA, and the sole representative of this genus besides the type species Aysheaia pedunculata, from the Cambrian (Stage 5) Stephen Formation, British Columbia. A redescription of Aysheaia prolata reveals previously overlooked morphological features, including segmental boundaries between putative lobopods, and curved terminal spines on the putative anterior end. These observations undermine lobopodian affinities of Aysheaia prolata , and instead we interpret this specimen as an isolated radiodontan frontal appendage. The presence of 11 podomeres, five of which possess elongate and anteriorly recurved ventral blades with auxiliary spines, together with shorter robust dorsal spines, identify the specimen as Stanleycaris. This represents the first report of Stanelycaris outside of the Cambrian Stage 5 thin Stephen Formation in British Columbia, expanding its palaeobiogeographic and stratigraphic range. Aysheaia is left as a monotypic genus endemic to the Burgess Shale. The Spence Shale luolishaniid Acinocrinus stichus is currently the only lobopodian known from the Cambrian of Utah.

Key words: Euarthropoda, Radiodonta, Hurdiidae, Cambrian, USA.

Stephen Pates [stephen.pates@zoo.ox.ac.uk], Department of Zoology, University of Oxford, Oxford, OX1 3PS, UK. Allison C. Daley [allison.daley@unil.ch], Institute of Earth Sciences, University of Lausanne, Géopolis, CH-1015, Lausanne,

Switzerland. Javier Ortega-Hernández [jo314@cam.ac.uk], Department of Zoology, Downing Street, University of Cambridge, Cambridge, CB2 3EJ, UK.

This is an open-access article distributed under the terms of the Creative Commons Attribution License (for details please see creativecommons.org), which permits unrestricted use, distribution, and reproduction in any medium, provided the original author and source are credited. 
FaFf Full text $(1,105.8 \mathrm{kB})$ 